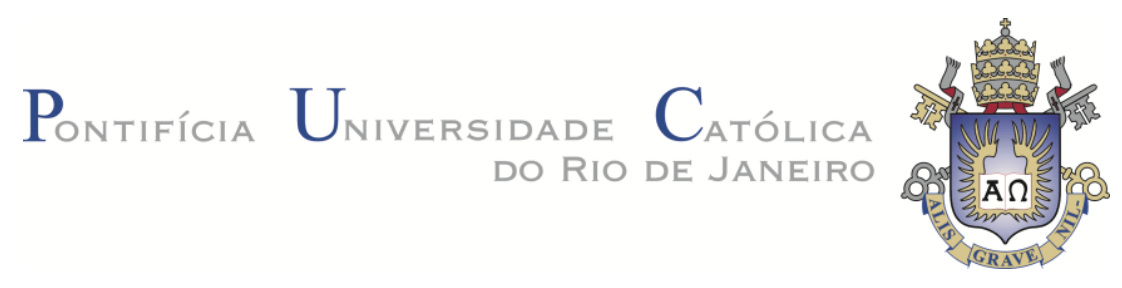

Ana Carolina Viana Silva

O lugar dos pais na clínica psicanalítica com crianças

Dissertação de Mestrado

Dissertação apresentada como requisito parcial para obtenção do título de Mestre pelo Programa de PósGraduação em Psicologia Clínica da PUC-Rio.

Orientadora: Prof $^{a}$ Ana Maria de Toledo Piza Rudge Rio de Janeiro

Agosto de 2012 


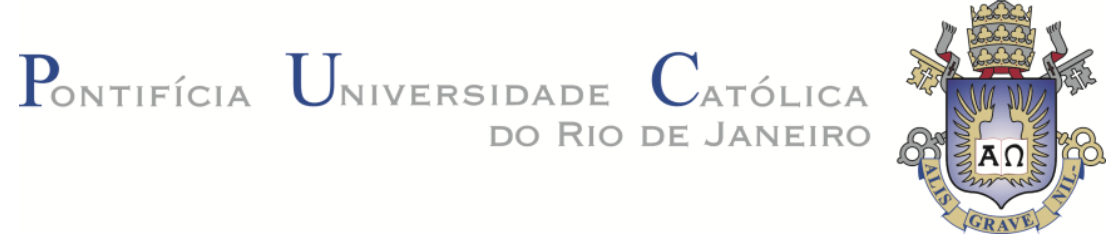

Ana Carolina Viana Silva

\title{
O lugar dos pais na clínica psicanalítica com crianças
}

Dissertação apresentada como requisito parcial para obtenção do título de Mestre pelo Programa de PósGraduação em Psicologia Clínica da PUC-Rio. Aprovada pela Comissão Examinadora abaixo assinada.

\author{
Profa. Ana Maria de Toledo Piza Rudge \\ Orientadora \\ Departamento de Psicologia da PUC-Rio
}

Profa. Silvia Maria Abu-Jamra Zornig

Departamento de Psicologia da PUC-Rio

Prof. Edson Saggese

Instituto de Psiquiatria da UFRJ

Profa. Denise Portinari

Coordenador Setorial de Pós-graduação

e Pesquisa do Centro de Teologia

e Ciências Humanas - PUC-Rio

Rio de Janeiro, 8 de Agosto de 2012 
Todos os direitos reservados. É proibida a reprodução total ou parcial do trabalho sem autorização da universidade, da autora e do orientador.

\section{Ana Carolina Viana Silva}

Graduada em Psicologia pela Universidade Federal do Maranhão em 2009. Especialista em Psiquiatria e Psicanálise com Crianças e Adolescentes pelo Instituo de Psiquiatria da Universidade Federal do Rio de Janeiro em 2012. Atuou como psicóloga clínica no Serviço de Psiquiatria da Infância e Adolescência do IPUB/UFRJ no período de 2010 a 2012.

Ficha Catalográfica

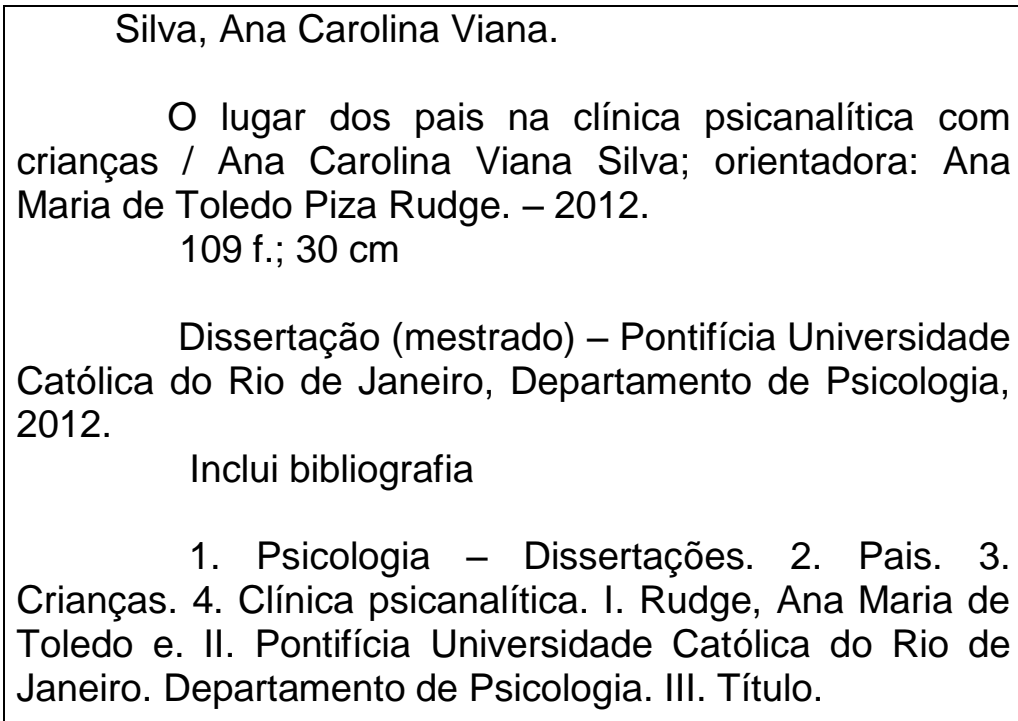

1. Psicologia - Dissertações. 2. Pais. 3. Crianças. 4. Clínica psicanalítica. I. Rudge, Ana Maria de Toledo e. II. Pontifícia Universidade Católica do Rio de Janeiro. Departamento de Psicologia. III. Título.

CDD: 150 
Para meus pais, Wilson e Lília, pelo amor e confiança que sempre me impulsionaram a buscar novos horizontes. 


\section{Agradecimentos}

Aos meus pais, Lília e Wilson, meus irmãos, Marília e Daniel, e a todos os familiares que sempre me encorajaram e me apoiaram com muito carinho nesta difícil jornada de estudar e morar fora.

À minha dinda, Lílian, pelo carinho e apoio fundamental à realização deste projeto de continuar minha formação.

À FAPEMA e à PUC-Rio, pelos auxílios concedidos durante o curso de mestrado, sem os quais este trabalho não seria realizado.

À Prof ${ }^{a}$ Ana Maria Rudge, pelo cuidado e atenção valiosos dedicados durante o acompanhamento do meu percurso no curso e orientação deste trabalho.

À minha segunda família: meus amigos Alexandra, Sophie, Pedro, Eduardo, Henrique, Cadu (meu revisor de todas as horas), Caroline Torres, Ana Paula, Clarissa, Talita, Rebeca, Marianas (Sant Anna e Teixeira), pelas alegrias e cumplicidades compartilhadas.

Aos colegas da PUC-Rio pelas angústias divididas.

Aos professores Edson Saggese e Sílvia Zornig por aceitarem contribuir na avaliação deste trabalho.

Aos professores e funcionários da Pós-Graduação - em especial à Marcelina pela dedicação e apoio nos momentos necessários. 


\section{Resumo}

Silva, Ana Carolina Viana; Rudge, Ana Maria de Toledo Piza. O lugar dos pais na clínica psicanalítica com crianças. Rio de Janeiro, 2012. 109p. Dissertação de Mestrado - Departamento de Psicologia, Pontifícia Universidade Católica do Rio de Janeiro.

O trabalho tem como objetivo investigar de que modo a questão da presença e do lugar dos pais na clínica psicanalítica com crianças está situada no campo teórico. Parte-se das formulações freudianas sobre a infância e o infantil, para em seguida, tratar-se da abertura do campo da psicanálise com crianças a partir da experiência do caso Hans publicado por Freud em 1909. Aborda-se o surgimento desta clínica, os debates entre Anna Freud e Melanie Klein, e desenvolvimentos posteriores com D.Winnicott, Françoise Dolto e Maud Mannoni. Finaliza-se com a discussão do problema da inserção dos pais no tratamento psicanalítico de crianças por meio da apresentação de ilustrações clínicas.

\section{Palavras-chave}

Pais; crianças; clínica psicanalítica. 


\section{Abstract}

Silva, Ana Carolina Viana; Rudge, Ana Maria de Toledo Piza (Advisor). The parents' place in the psychoanalytic treatment of children. Rio de Janeiro, 2012. 109p. MSc. Dissertation - Departamento de Psicologia, Pontifícia Universidade Católica do Rio de Janeiro.

The study aims to investigate how the problem of parents place and presence in the children psychoanalitic treatment lies in the theoretical field. It starts with the Freudian formulations about childhood and child, to then it discusses the opening of the field of psychoanalysis with children from the experience of Hans case published by Freud in 1909. It approaches the emergence of this treatment, the appearance of clinical discussions between Anna Freud and Melanie Klein, and further studies with D.Winnicott, Françoise Dolto and Maud Mannoni. It ends with a discussion about the problem of parents inclusion in the children psychoanalytic treatment through the presentation of clinical illustrations.

\section{Palavras-chave}

Parents; children; clinical psychology. 


\section{Sumário}

$\begin{array}{ll}\text { 1. Introdução } & 10\end{array}$

2. O infantil e o psiquismo na teoria freudiana 15

2.1 Da infância ao infantil na psicanálise 15

2.2 Angústia, desamparo e excesso pulsional 20

3. A análise de criança em Freud: O caso Hans ou abrindo o campo da psicanálise com crianças 25

4. A clínica psicanalítica com crianças: consequências teóricas 34

4.1 As pioneiras na clínica: da "experiência pedagógica" em Anna Freud à técnica do brincar em Melanie Klein 34

4.2 Winnicott: a função do ambiente e o espaço transicional 49

4.3 A criança, o sintoma e a linguagem: das repercussões do ensino de Lacan na clínica com crianças.

5. Os pais no tratamento psicanalítico de crianças 74

5.1 Experiências Clínicas: $\quad 80$

5.1.1 Joana e a separação 81

5.1.2 Lucas 86

5.1.3 Caio e os fantasmas 90

6. Considerações finais 99

7. Referências Bibliográficas 102 
Tom: "Por que nós dizemos preces?"

Pai: "Para falar com Deus." Tom: "O que é Deus?"

Pai: (fazendo o melhor possivel) "Bem: $2+2=4$. Isso é uma coisa verdadeira. A gravidade é um fato. Essas coisas são Deus". (etc)

Tom: "Por que as coisas crescem?"

Pai: "Porque elas querem crescer. Por que você cresce?"

Tom: "Porque eu estou vivo e vim da barriga da mamãe."

Pai: "E de onde ela veio?"

E assim foi, da evolução ao sexo. Depois eles riram, porque chegaram a um ponto em que a resposta foi: "Nenhum de nós sabe. Como isso tudo começou? Bem, é aqui que entra Deus."

Tom: Então, não saber, isso é Deus."

(Winnicott, sem data. In: SHEPHERD, 1997, p.112) 